\title{
Geographical structuring and low diversity of paternal lineages in Bahrain shown by analysis of 27 Y-STRs
}

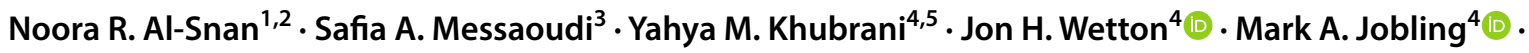 \\ Moiz Bakhiet ${ }^{1}$
}

Received: 27 January 2020 / Accepted: 8 June 2020 / Published online: 25 June 2020

(c) The Author(s) 2020

\begin{abstract}
We have determined the distribution of Y-chromosomal haplotypes and predicted haplogroups in the ethnically diverse Kingdom of Bahrain, a small archipelago in the Arabian Gulf. Paternal population structure within Bahrain was investigated using the 27 Y-STRs (short tandem repeats) in the Yfiler Plus kit to generate haplotypes from 562 unrelated Bahraini males, sub-divided into four geographical regions-Northern, Capital, Southern and Muharraq. Yfiler Plus provided a significant improvement over the 17-locus Yfiler kit in discrimination capacity (from $77 \%$ to $87.5 \%$ overall), but discrimination capacity differed widely between regions from $98.4 \%$ in Muharraq to $75.2 \%$ in the Northern region, an unusually low value possibly resulting from recent rapid population expansion. Clusters of closely related male lineages were seen, with only $79.4 \%$ of donors displaying unique haplotypes and 59\% of instances of shared haplotypes occurring within, rather than between, regions. Haplogroup prediction indicated diverse origins of the population with a predominance of haplogroups J2 and J1, both typical of the Arabian Peninsula, but also haplogroups such as B2 and E1b1a likely originating in Africa, and $\mathrm{H}, \mathrm{L}$ and R2 likely indicative of migration from South Asia. Haplogroup frequencies differed significantly between regions, with J2 significantly more common in the Northern region compared with the Southern, possibly due to differential settlement by Baharna and Arabs. Our study shows that paternal lineage population structure can exist even over small geographical scales, and that highly discriminating genetic tools are required where rapid expansions have occurred within tightly bounded populations.
\end{abstract}

Keywords Bahrain $\cdot$ Y-STRs $\cdot$ Haplogroup $\cdot$ Population structure $\cdot$ Haplotype

\section{Introduction}

Communicated by Stefan Hohmann.

Electronic supplementary material The online version of this article (https://doi.org/10.1007/s00438-020-01696-4) contains supplementary material, which is available to authorized users.

Noora R. Al-Snan

nr.alsnan@interior.gov.bh

$\triangle$ Jon H. Wetton

jw418@le.ac.uk

1 Department of Molecular Medicine, College of Medical and Medicine Sciences, Arabian Gulf University, Manama, Kingdom of Bahrain

2 Forensic Science Laboratory, Directorate of Forensic Science, General Directorate of Criminal Investigation and Forensic Science, Ministry of Interior, Manama, Kingdom of Bahrain
The Kingdom of Bahrain is an archipelago totaling just 765 square kilometers, located northwest of the State of Qatar, and east of the Kingdom of Saudi Arabia; further to the north and east lies the Islamic Republic of Iran (Abdulla

3 Forensic Sciences Department, College of Criminal Justice, Naif Arab University for Security Sciences, Riyadh, Saudi Arabia

4 Department of Genetics and Genome Biology, University of Leicester, University Road, Leicester, UK

5 Forensic Genetics Laboratory, General Administration of Criminal Evidence, Public Security, Ministry of Interior, Riyadh, Saudi Arabia 
and Zain al Abdeen 2009) (see Fig. 1). Bahrain's population stood at $\sim 1.6$ million in 2019, of which less than half are Bahraini citizens (www.worldometers.info), distributed primarily on the main islands of Bahrain, Muharraq, Umm al-Naasan and Sitra (Hitti and Murgotten 1916). Its coastal location in the Arabian Gulf, fertile land and abundance of fresh water have attracted many migrants resulting in an ethnically diverse society with origins both in the Arabian Peninsula and places further afield such as Iran and India (Holes 2001). Bahrain's pre-Islamic population consisted of Christian Arabs, Persians (Zoroastrians), Jews, and Aramaic-speaking agriculturalists (Lawson 1989) and now comprises four main ethnic groups: Arabs, Baharna (the putative indigenous peoples) and Persians (Huwala and Ajam) which are distributed unevenly between the four Governorates (Capital, Muharraq, Northern and Southern) (al-Khūrī 1980; Fuccaro 2009). The Arabs have traditionally lived in areas such as Zallaq, Hawar Islands, Riffa (all in the Southern Governorate) and Muharraq. The Ajam, who are ethnic Persians (McCoy 2008), and Baharna, the Arabized descendants of the pre-Islamic population, form large communities in the Capital Governorate, Muharraq and in some parts of the Northern Governorate. Muharraq and Riffa also have significant numbers of Huwala, descendants of migrant Arabs many of whom had journeyed from the Arabian Peninsula to Iran in the eighteenth or nineteenth centuries, largely returning between 1850 and 1900, as well as Bahrainis of Balochi descent and others of East African origin (Lawson 1989).

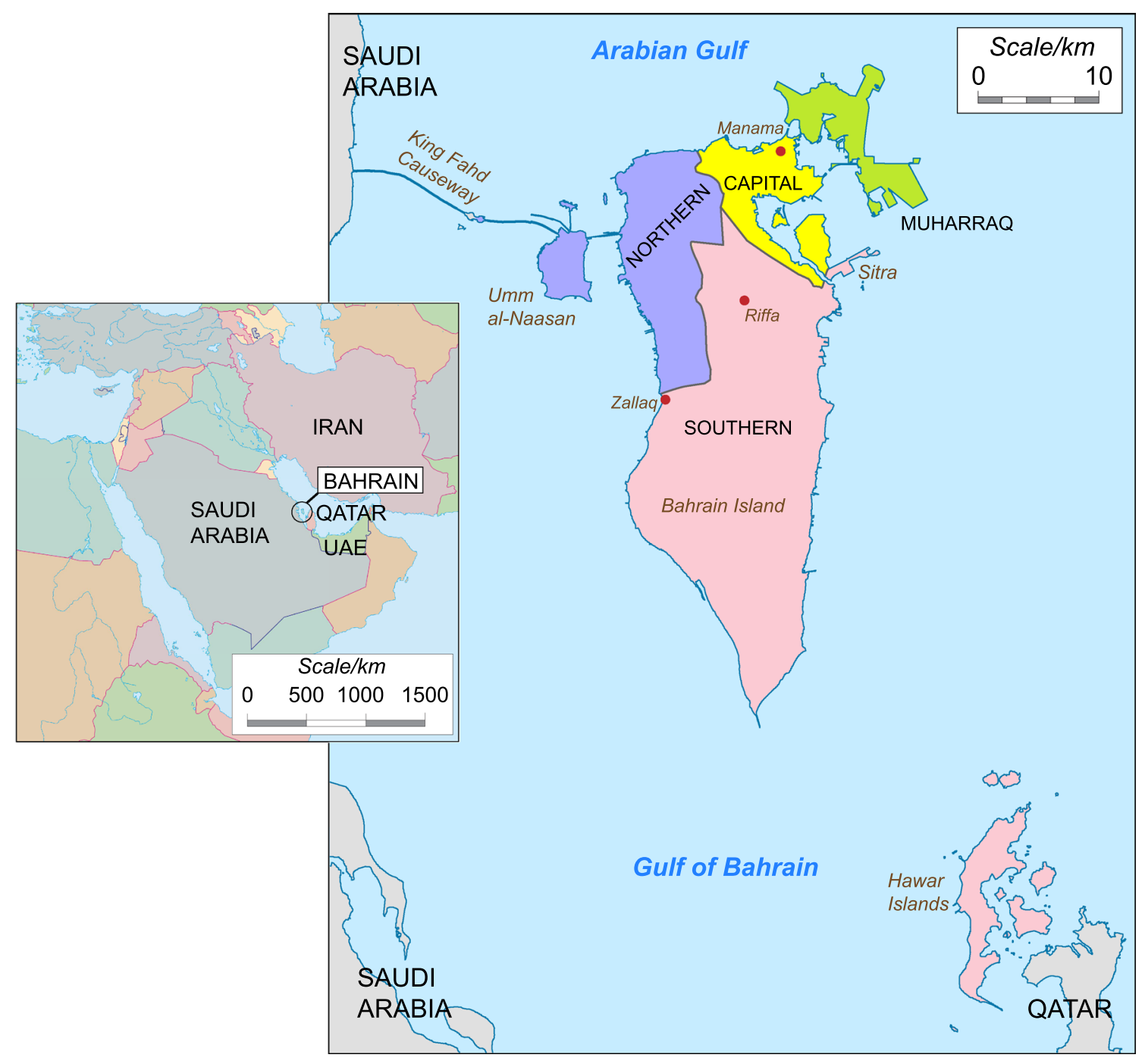

Fig. 1 Map of Bahrain. The main map shows the location of places mentioned in the text, and the four governorates used as a basis for sample subdivision. The inset map to the left shows the position of Bahrain in its regional context. UAE: United Arab Emirates. Main map adapted from commons.wikimedia.org/wiki/File:Bahrain, administrative_divisions_-_de_-_colored.svg (GNU Free Documentation License: commons.wikimedia.org/wiki/Commons:GNU_Free_ Documentation_License,_version_1.2). Inset map from Mountain High Map Frontiers ${ }^{\mathrm{TM}}$ version 94.01 (Mountain High Maps ${ }^{\circledR}$ Copyright $(1993$ Digital Wisdom®, Inc.; www.digiwis.com/dwi_frl.htm) 
This geographical and social organization might be expected to have an effect on patterns of genetic diversity, particularly considering the male-specific region of the $\mathrm{Y}$ chromosome (MSY), which tends to show pronounced geographic variation (de Knijff et al. 1997; Roewer 2009; Ballantyne and Kayser 2012). To date, genetic studies of the Bahraini population have been limited and little has been done to characterize population structure within the Kingdom.

Here we use the Yfiler Plus kit to characterize Y-STR (short tandem repeat) haplotypes in 562 unrelated male Bahraini citizens sub-divided by geographical region; the same samples have been previously typed with autosomal STRs (Al-Snan et al. 2019). The 6-dye Yfiler Plus PCR Amplification kit detects 27 Y-STR loci: DYS19, DYS385a/b, DYS389I/II, DYS390, DYS391, DYS392, DYS393, DYS437, DYS438, DYS439, DYS448, DYS456, DYS458, DYS460, DYS481, DYS533, DYS635 (Y-GATA-C4), Y-GATA-H4, DYF387S1a/b, DYS449, DYS518, DYS570, DYS576 and DYS627, with the last seven loci being 'rapidly mutating Y-STRs' (RM Y-STRs). These RM Y-STRs, which were not detected by the original Yfiler multiplex, are particularly useful for distinguishing between closely related males (Ballantyne et al. 2010, 2014; Adnan et al. 2016) and increase the likelihood of discrimination in populations that have grown very rapidly often from small numbers of patrilineally-related tribal groups (Khubrani et al. 2018).

\section{Materials and methods}

\section{Sample collection}

Blood spots were collected on Nucleic-Cards (Copan, Italy) from 562 unrelated Bahraini males whose ancestry to the level of paternal grandfather was assigned to one of four administrative subdivisions of the country (Capital, Muharraq, Northern and Southern Governorates). Donors ranging in age from 20 to 55 years were recruited through social media channels such as Twitter and Instagram and invited to the General Directorate of Criminal Investigation and Forensic Science-Kingdom of Bahrain to submit blood samples. Ethical review for the study was provided by the Research and Research Ethics Committee (RREC) (E007-PI-10/17) in the Arabian Gulf University, and informed consent was provided by all participants along with details sufficient to exclude individuals sharing ancestry closer than paternal great grandfather.

\section{DNA amplification and fragment detection}

DNA was obtained from 1.2-mm diameter discs punched from blood-spots using the easyPunch STARlet system (Hamilton). A total of 27 Y-STRs were directly amplified with the Yfiler Plus Amplification Kit using 28 PCR cycles according to manufacturer's recommendations on a Veriti 96-well Thermal Cycler (Thermo Fisher Scientific). The PCR products $(1 \mu \mathrm{l})$ were separated by capillary electrophoresis in an ABI 3500xl Genetic Analyzer along with LIZ600 size standard v2 in a Hi-Di Formamide master mix (all Thermo Fisher Scientific). GeneMapper ID-X Software $\mathrm{v} 1.4$ was used for genotype assignment using the allelic ladders provided with the Yfiler Plus kit following ISFG recommendations (Gusmão et al. 2017). Samples displaying non-standard patterns, off-ladder and microvariant alleles were repeated. The resulting profiles were submitted to the Y-chromosomal Haplotype Reference Database (YHRD) (Roewer 2017) under the following accession numbers: Capital Governorate YA004556, Northern Governorate YA004557, Southern Governorate YA004558 and Muharraq Governorate YA004559.

\section{Statistical analysis}

\section{Forensic and population genetic parameters}

Haplotype information (number of haplotypes, number of unique haplotypes, discriminatory capacity and haplotype diversity) was calculated using STRAF (Gouy and Zieger 2017). Genetic diversity (GD) was calculated according to Nei and Tajima (1981), haplotype match probability (HMP) was calculated as the sum of the squared haplotype frequencies, and the discriminatory capacity (DC) was calculated as the ratio between the number of different haplotypes and the total number of haplotypes. Haplotype diversities (HD) were calculated as one minus the HMP multiplied by the number of haplotypes, divided by the number of haplotypes minus one.

Genetic distances between populations were evaluated using the $R_{\mathrm{ST}}$ statistic, and visualized through multi-dimensional scaling (MDS) plots using comparative population data and the calculation tool within the online YHRD (Willuweit and Roewer 2015). Population differentiation tests based on predicted haplogroup frequencies were carried out within Arlequin (Excoffier and Lischer 2010).

For all statistical analyses, the repeat number of DYS389I was subtracted from that of DYS389II so that its diversity was not considered twice.

\section{Haplogroup prediction}

The NevGen Y-DNA Haplogroup Predictor (Ćetković and Nevski 2016), based on a previously-implemented Bayesian approach (Athey 2006), was used to derive likely Y-SNP haplogroups from Y-STR haplotypes (Ćetković and Nevski 2016). The software bases the prediction upon length variation at the 23 loci in the Promega PowerPlex Y23 multiplex, 
so DYS549 and DYS643 (which are not amplified by Yfiler Plus) were coded as missing data. While the Predictor allocates haplotypes to one of 484 sub-branches of the Y haplogroup tree, we have restricted our level of assignments to major haplogroups which we have previously shown can be accurately predicted in Arabian Peninsula populations (Karafet et al. 2008; Khubrani et al. 2018).

\section{Median-joining networks}

Median-joining networks of haplotypes were constructed using the program Network v. 5.0.1.1 (Bandelt et al. 1999) with weightings based on the inverse variance of repeat length at each locus in order to reduce reticulation. The duplicated loci DYS385a/b and DYF387S1a/b were excluded from the network construction as it is not possible to associate particular alleles to specific copies.

\section{Results}

\section{Haplogroup prediction and median-joining networks}

A median-joining network based solely on allele length differences among the haplotypes of the 562 Bahraini males displays several distinct branches as shown in Fig. 2. An almost perfect correspondence was noted between these and the haplogroup predictions. Haplogroup prediction suggests that haplogroup $\mathrm{J} 2$ is the most common in the Bahraini population encompassing $27.6 \%$ of the sample, followed by $\mathrm{J} 1$ (23.0\%), E1b1b (8.9\%), E1b1a (8.6\%) and R1a (8.4\%), with other predicted haplogroups (G, T, L, R1b, Q, R2, B2, $\mathrm{E} 2, \mathrm{H}$ and $\mathrm{C}$ ) occurring at progressively lower frequencies. The profiles of 20 men were assigned a low haplogroup fitness $(<25)$ by the NevGen software, and also received a high probability of haplogroup misassignment (>97.5\%) because there were no closely matching haplotypes of known

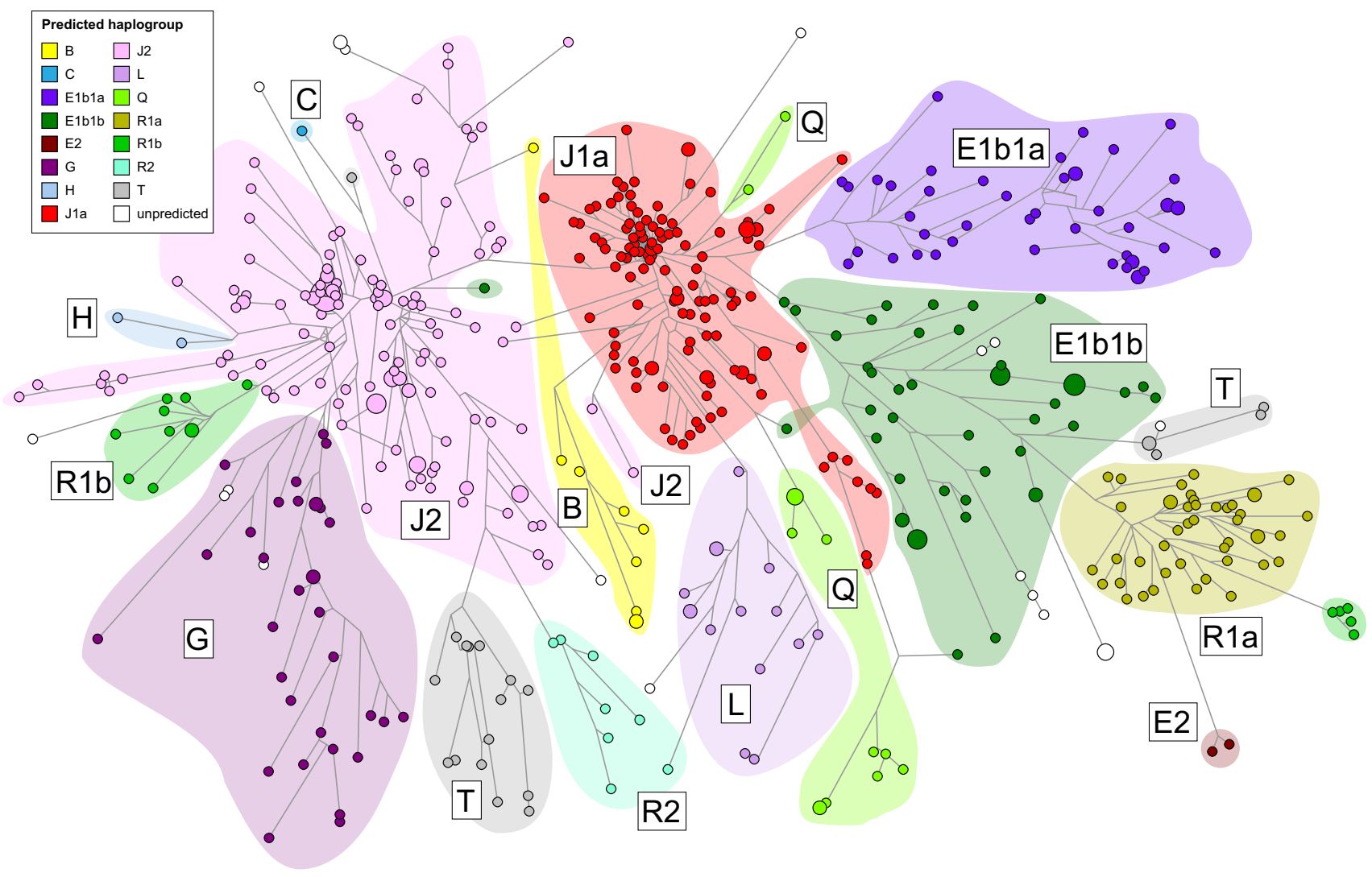

Fig. 2 Median-joining network based upon Yfiler Plus haplotypes from 562 Bahraini males showing concordance of NevGen haplogroup predictions with the branching structure. Nodes represent haplotypes, with node size proportional to the number of men sharing the haplotype. Lines connecting nodes have lengths proportional to the number of mutational steps with the shortest line corresponding to a difference of one repeat unit at a single locus. Each node is colored according to its NevGen haplogroup prediction as shown in the key, including 20 haplotypes having a probability of inappropriate prediction greater than $97.5 \%$ which are shown as white, unpredicted (UP) nodes. Shapes enclose groups of haplotypes predicted to belong to the same major haplogroup as indicated by the adjacent labels 
Table 1 Sub-regional affiliations of predicted Y-haplogroups for 562 Bahraini males

\begin{tabular}{lrllrrrrrrrrrrrrrr}
\hline Haplogroup & $n$ & B & C & E1b1a & E1b1b & E2 & G & H & J1 & J2 & L & Q & R1a & R1b & R2 & T & UP \\
\hline Capital & $\mathbf{1 0 0}$ & 1 & & 12 & 9 & 1 & 1 & & 19 & 30 & 2 & 4 & 8 & 2 & & 5 & 6 \\
Muharraq & $\mathbf{1 2 8}$ & 2 & & 4 & 13 & & 11 & 2 & 33 & 22 & 5 & 3 & 18 & 7 & 1 & 5 & 2 \\
Northern & $\mathbf{2 5 4}$ & 3 & 1 & 19 & 24 & & 17 & & 56 & 85 & 7 & 4 & 12 & 3 & 6 & 7 & 10 \\
Southern & $\mathbf{8 0}$ & 3 & & 11 & 6 & 1 & 4 & 21 & 13 & 1 & 3 & 7 & 3 & 1 & 4 & 2 \\
Bahrain & $\mathbf{5 6 2}$ & 9 & 1 & 46 & 52 & 2 & 33 & 2 & 129 & 150 & 15 & 14 & 45 & 15 & 8 & 21 & 20 \\
\hline
\end{tabular}

Number of individuals are shown in bold

$n$ number of individuals, UP unpredicted haplogroup

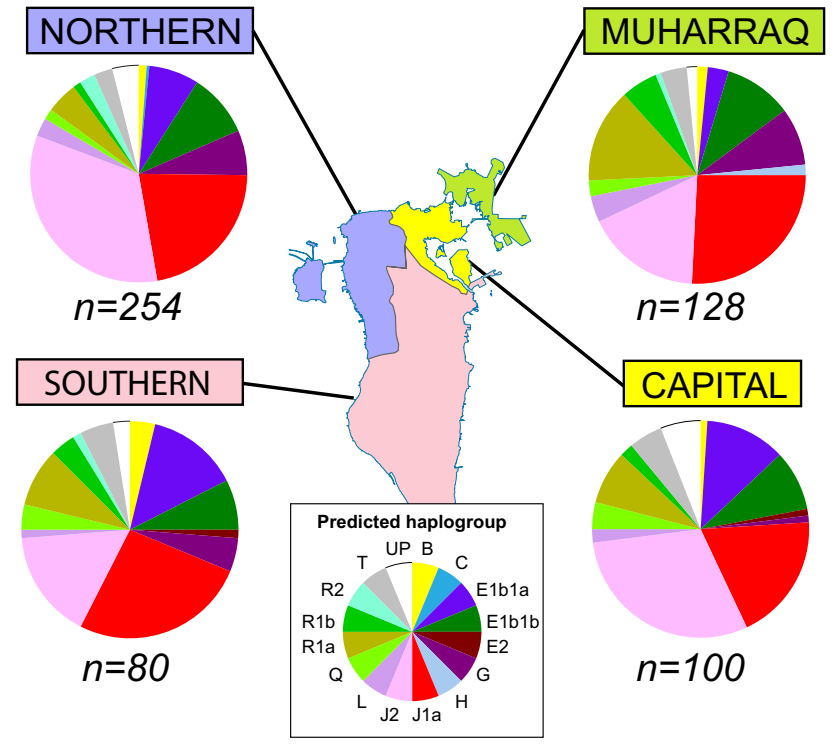

Fig. 3 Proportions of predicted haplogroups observed in the four governorates of Bahrain. Sector area in the pie-charts indicates the frequency of predicted haplogroups, as shown by colors in the key below. Sample sizes $(n)$ for each governorate are also given

haplogroup within the NevGen prediction model; these were therefore designated as unpredicted (UP).

Haplogroup predictions allow comparison with SNPdefined lineages that are known from published studies to differ significantly in frequency between countries. Table 1 and Fig. 3 and Online Resource 1 demonstrate that haplogroup frequency differences also exist between governorates. The ratio of haplogroup J1 to J2 shows clear sub-population differences (Fisher's Exact Test $P=0.012$ ). Haplogroup J1 is most frequent in the Southern Governorate (27\%) where the highest proportion of Arabs live, and in the Muharraq Governorate $(27 \%)$ where many migrant Huwala Arabs resettled, and it declines to its lowest frequency in the Northern and Capital Governorates (21\% and 19\%). By contrast, the Northern and Capital Governorates where the Baharna and Ajam are most represented show higher frequencies of haplogroup J2 (34\% and 31\%) than in Muharraq and the Southern Governorate (both 17\%).
Table $2 F_{\text {ST }}$ values for pairwise comparisons of predicted haplogroup frequency

\begin{tabular}{lllll}
\hline & Capital & Northern & Muharraq & Southern \\
\hline Capital & 0 & $0.3603 \pm 0.058$ & $\mathbf{< 0 . 0 0 0 0 1}$ & $0.1441 \pm 0.034$ \\
Northern & 0 & 0 & $<\mathbf{0 . 0 0 0 0 1}$ & $0.0180 \pm 0.012$ \\
Muharraq & 0.01586 & 0.01906 & 0 & $0.3784 \pm 0.030$ \\
Southern & 0.00555 & 0.01599 & 0.00051 & 0 \\
\hline
\end{tabular}

$F_{\text {ST }}$ values for pairwise comparisons of predicted haplogroup frequency shown below the diagonal, and probabilities shown above; those which were significant after Bonferroni correction are shown in bold

Pairwise $\mathrm{F}_{\mathrm{ST}}$ based on predicted haplogroup frequencies shows that the greatest overall differences are between Muharraq and Northern Governorates $\left(F_{\mathrm{ST}}=0.01906\right.$, $P<0.0001)$ and Muharraq and Capital Governorates $\left(F_{\mathrm{ST}}=0.01586, P<0.0001\right)$ with other comparisons not reaching formal significance after Bonferroni correction (Table 2). Similarly, Fisher's Exact Tests of population differentiation highlighted the same pairs as being significant with the comparison between the Northern and Southern Governorates once again failing to reach significance after Bonferroni correction. A similar pattern was seen when considering $R_{\mathrm{ST}}$ based on the Y-STR haplotypes themselves but in this case while Muharraq and Northern Governorates $\left(R_{\mathrm{ST}}=0.01179, P<0.0001\right)$ remained highly significant, the other comparisons were not significant following Bonferroni correction (Table 3).

\section{Y-STR allele and haplotype diversity}

Microvariant alleles aligning with the Yfiler Plus virtual allelic ladder were detected in 141 samples; 129 samples displayed '.2' microvariants at DYS458 (14.2, 16.2, 17.2, $18.2,19.2,20.2,21.2$ and 22.2), which corresponded exactly with haplotypes predicted to belong to haplogroup J1 in concordance with the well-established association between intermediate length (.2) DYS458 alleles and this haplogroup (Ferri et al. 2008; Khubrani et al. 2018). Four samples displayed .2 microvariants present 
Table $3 R_{\mathrm{ST}}$ values for pairwise comparisons of haplotypes between populations

\begin{tabular}{lllll}
\hline & Capital & Northern & Muharraq & Southern \\
\hline Capital & 0 & $0.0811 \pm 0.037$ & $0.0451 \pm 0.020$ & $0.3333 \pm 0.051$ \\
Northern & 0.00404 & 0 & $<\mathbf{0 . 0 0 0 0 1}$ & $0.0180 \pm 0.012$ \\
Muharraq & 0.00736 & 0.01179 & 0 & $0.2162 \pm 0.043$ \\
Southern & 0.00211 & 0.00894 & 0.00182 & 0 \\
\hline
\end{tabular}

$R_{\mathrm{ST}}$ values for pairwise comparisons of haplotypes between populations shown below the diagonal, and probabilities shown above; those which were significant after Bonferroni correction are shown in bold in the DYF387S1 virtual ladder (39.2 and 41.2), and all were predicted to belong to haplogroup B2 which is often associated with such microvariants at this locus (Iacovacci et al. 2017). Similarly, a DYS481 25.1 microvariant allele in five men was wholly concordant with the NevGen prediction of the R1b-PH155 subclade, which is a globally rare basal $\mathrm{R} 1 \mathrm{~b}$ lineage previously recorded in several Bahrainis who have very similar haplotypes to those typed here, and have submitted their Y-STR and Y-SNP profiles to the YFull Tree database (Roewer 2017; Xie et al. 2019). The same allele (25.1) has also been recorded in a Han Chinese individual who was derived for the Y-SNP M343 but ancestral for SNP L389, which also implies a basal R1b lineage (Guo 2017).

Several off-ladder (OL) alleles were designated after comparison with the allelic ladder. Six OL alleles were detected at DYF387S1; a single example of 36.3 in a predicted G2a haplotype, 35.2 in two individuals sharing an identical haplotype predicted to belong to haplogroup R1a, and a single instance of 44.2 and two occurrences of 42.2 in three different predicted B2a haplotypes (these representing OL variants of the previously mentioned association of .2 alleles with the $\mathrm{B} 2$ haplogroup). Two occurrences of the $\mathrm{OL}$ DYS570 allele 14.3 were found in closely related haplotypes predicted to belong to haplogroup $\mathrm{J} 1 \mathrm{a}$, and differing by a single repeat at each of four loci. Three OL alleles were detected at DYS449 (two instances of 34.2 and a single 32.1) all within closely-related predicted E1b1 lineages. The clustering of intermediate alleles is shown in the median-joining network in Fig. S2.

An unusual finding was an OL peak of 219 bp within the DYS19 size range in association with a standard DYS19 allele 15. This donor lacked a peak within the expected size range of DYS448 which shares the same dye, raising the possibility that the OL peak is the result of an unusually large internal deletion producing a DYS448 allele 4 . The donor was predicted to belong to haplogroup J2a, which typically has alleles in the range of 19-23 repeats (309-334 bp). The common structure of alleles at this locus comprises two variable length (AGAGAT) ${ }_{\mathrm{n}}$ hexamer repeats separated by a 42-bp "non-variable" region of seven diverged hexamer repeats; the observed OL peak is appropriately sized to have resulted from the loss of between 15 and 19 hexamer repeats.
A similar event has been reported previously by Budowle et al. (Budowle et al. 2008). As well as this "pseudo-null" DYS448 allele, a true null allele was detected at DYS439 in a donor of unpredicted haplogroup.

Duplications at DYF387S1 produced two instances of triallelic patterns similar to those reported in several populations (Ye et al. 2015; Pickrahn et al. 2016; Wang et al. 2016; Iacovacci et al. 2017; Spólnicka et al. 2017; Watahiki et al. 2019). In one predicted haplogroup J1a male the alleles 36 , 37 and 38 were all detected with equal strength implying an equal copy number, as would be seen if just one DYF387S1 copy had been duplicated. A second donor who was predicted as haplogroup E1b1b-V13 displayed alleles 35, 36 and 37 , but the allele 35 peak was double the height of the others, implying that there were four copies of the locus in this individual. The different haplogroup affiliations show that duplications in this region are recurrent, and have varied consequences.

Another possible mutational event associated with duplicated STR loci is gene conversion leading to the homogenization of the repeat number between two copies (Balaresque et al. 2014). This process may explain why two predicted haplogroup B2 individuals share a Y-STR haplotype containing only a 37-repeat DYF387S1 peak. The other seven predicted B2 haplotypes in this study all display one copy of DYF387S1, with an integer number of repeats differing by at least three repeats from an intermediate (.2) copy as is frequently observed in other B2 lineages (Iacovacci et al. 2017). It is likely there was a gene conversion back to the ancestral (integer) state earlier in the paternal lineage of these two men.

The complete haplotype list and diversity summary statistics are provided for the four sub-populations (Online Resource 1 and Table 4, respectively). As expected, the number of haplotypes was considerably increased by the ten additional loci compared with the earlier Yfiler multiplex; 492 distinct Yfiler Plus haplotypes were detected in the 562 samples. Of these, 446 haplotypes were observed once (90.7\%), and there were 33 identical pairs, eight trios, three quartets, one quintet and one haplotype shared nine times.

Considering all the Yfiler Plus loci the proportion of donors within the national sample with unique haplotypes was $79.4 \%$, declining to $63.7 \%$ when only the Yfiler loci 
Table 4 Diversity summary statistics for Y-STR haplotypes, considering region of recruitment

\begin{tabular}{|c|c|c|c|c|c|c|c|c|c|c|c|c|c|c|}
\hline Population & $n^{*}$ & No. unique hts & No. pair hts & No. trio hts & 4 & 5 & 6 & 9 & 13 & 19 & HMP & $\begin{array}{l}\text { Haplotype } \\
\text { Diversity }\end{array}$ & $\%$ unique hts & $\mathrm{DC}$ \\
\hline \multicolumn{15}{|c|}{ Yfiler Plus Amplification Kit } \\
\hline All & 562 & 446 & 33 & 8 & 3 & 1 & & 1 & & & 0.0025 & 0.9992 & 79.4 & 87.5 \\
\hline Capital & 100 & 90 & 5 & & & & & & & & 0.0110 & 0.9990 & 90.0 & 95.0 \\
\hline Muharraq & 128 & 124 & 2 & & & & & & & & 0.0081 & 0.9998 & 96.9 & 98.4 \\
\hline Northern & 254 & 191 & 16 & 4 & 2 & 1 & 1 & & & & 0.0060 & 0.9980 & 75.2 & 84.6 \\
\hline Southern & 80 & 71 & 3 & 1 & & & & & & & 0.0144 & 0.9981 & 88.8 & 93.8 \\
\hline \multicolumn{15}{|c|}{ Yfiler loci only } \\
\hline All & 562 & 359 & 49 & 17 & 5 & 3 & & & & 1 & 0.0039 & 0.9979 & 63.9 & 77.0 \\
\hline Capital & 100 & 78 & 6 & 2 & 1 & & & & & & 0.0136 & 0.9964 & 78.0 & 87.0 \\
\hline Muharraq & 128 & 108 & 10 & & & & & & & & 0.0090 & 0.9988 & 84.4 & 92.2 \\
\hline Northern & 254 & 165 & 17 & 8 & 2 & 2 & & & 1 & & 0.0087 & 0.9952 & 65.0 & 76.4 \\
\hline Southern & 80 & 67 & 5 & 1 & & & & & & & 0.0150 & 0.9975 & 83.8 & 91.3 \\
\hline
\end{tabular}

Number of individuals are shown in bold

* $n$ number of individuals, $h t s$ haplotypes, $H M P$ haplotype match probability, $D C$ discrimination capacity. Yfiler comparison: lists statistics considering only those STRs included in the 17-STR Yfiler kit

were analyzed. The diverse Muharraq Governorate had the highest percentage of unique haplotypes $(96.9 \%$ for Yfiler Plus, reducing to $84.4 \%$ for Yfiler), while the lowest percentage bearing unique haplotypes was seen in the Northern Governorate (75.2\% reducing to $64.6 \%$ at the Yfiler loci). The majority of shared haplotypes were shared within rather than between regions (59\% against an expectation of $31 \%$ if lineages were randomly dispersed across the governorates) and clusters of related haplotypes also appear more frequently within rather than across governorates (see Fig. S1).

This was naturally reflected in the discriminatory capacity (DC), where the national value for the Yfiler Plus loci was $87.5 \%$, considerably higher than when considering Yfiler (77.0\%). Regarding the subpopulations, Muharraq Governorate recorded the highest DC $(98.4 \%)$ followed by Capital Governorate $(95.0 \%$ ), with Northern Governorate the lowest at $84.6 \%$.

\section{MDS analysis}

AMOVA was used to explore population differentiation with pairwise genetic distances $\left(R_{\mathrm{ST}}\right)$ visualized by multidimensional scaling (MDS), between the four Governorates of Bahrain and relevant neighboring population samples obtained from YHRD Release R61 (Fig. 4). Comparisons were performed using only the Yfiler loci, as Yfiler Plus data were not available for Iran, the region from which a significant proportion of the Bahraini population originates. Muharraq shows a greater degree of similarity to Iran whereas Southern, Northern and Capital populations were closer to Emirati and Saudi populations, which correlated with results obtained by comparison with autosomal profiles derived from the same individuals (Al-Snan et al. 2019).

Muharraq also fell closest to the only Bahraini data previously submitted to YHRD (YA004278, N=156 Yfiler Plus profiles) although the sub-regional origins of the donors to that study are unknown.

\section{Discussion}

While the addition of a number of RM Y-STRs greatly increased the discrimination capacity (DC) compared with the Yfiler multiplex previously implemented in Bahrain, a DC of $87.5 \%$ remains very low compared with most populations, for example Serbia 99.9\% (Zgonjanin et al. 2017), Upper Austria and Salzburg 99.7\% (Pickrahn et al. 2016), Mongolia 98.9\% (Wang et al. 2019), Italy 98.5\% (Rapone et al. 2016), US Caucasians 98.5\% (Gopinath et al. 2016), Daur 96.55\% (Wang et al. 2019) and Saudi Arabia 95.3\% (Khubrani et al. 2018), although the highly bottle-necked Greenland population is lower at $79.0 \%$ (Olofsson et al. 2015). There are many shared haplotypes in the Bahraini sample, despite precautions to exclude males sharing common patrilineal ancestry in the last three generations. This is likely the result of an extended period of rapid population expansion since the discovery of oil in the early 1930 s. Increased prosperity since then has led to improvements in health care and a significantly reduced childhood mortality rate which, combined with a predominantly youthful population, has resulted in Bahrain having the tenth most rapidly growing population in the world (Al-Arrayed and Hamamy 2012). 


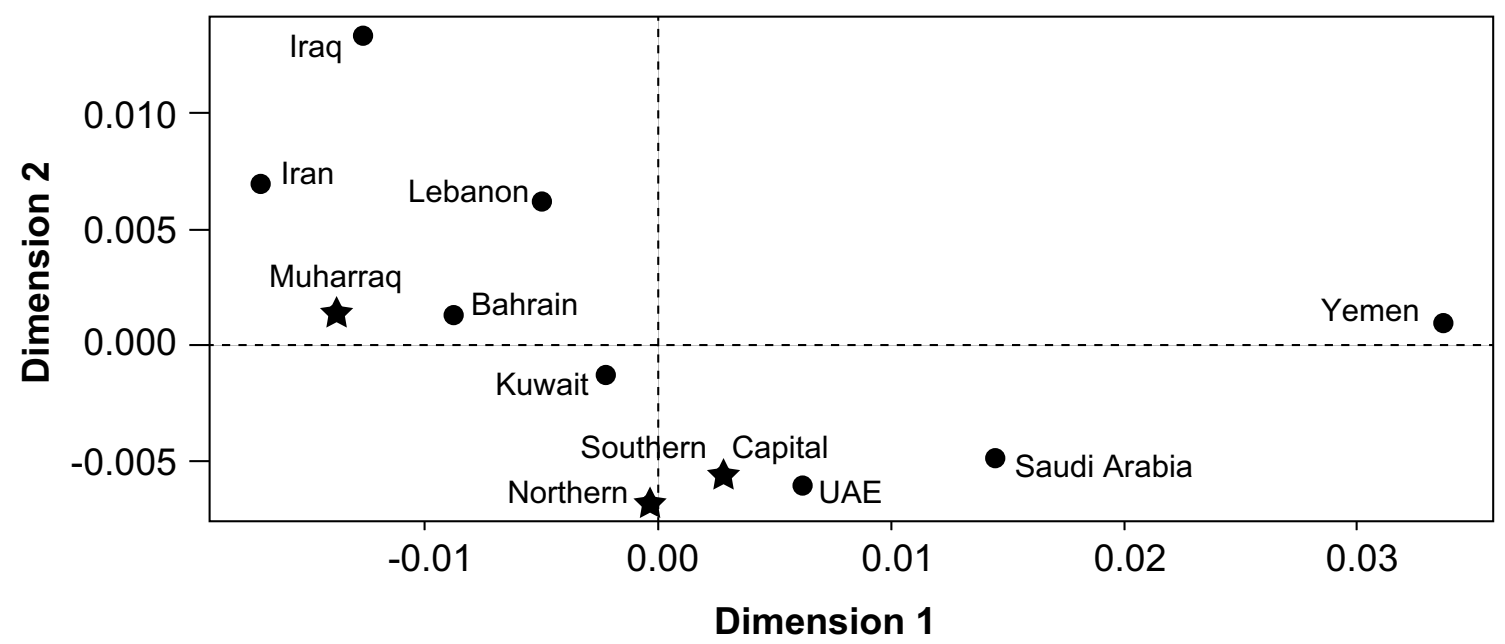

Fig. 4 Multidimensional scaling (MDS) plot showing relationships between Bahraini and other populations. Comparison with other datasets required reduction of the number of STRs to a shared set of seventeen (Yfiler loci). Comparison is shown of the four governorate samples from the current study (stars) with an independent dataset of 156 Y-STR haplotypes from the same country ('Bahrain' (YHRD

Lying at the crossroads of Europe, Asia and Africa, the genetic landscape of Bahrain has been shaped by migrants from many other regions. Prior to the opening in 1986 of a 25-km causeway to Saudi Arabia (Fig. 1), all international contact had been via maritime routes through the Arabian Gulf. Unlike its immediate neighbors Saudi Arabia and Qatar, where haplogroup J1 predominates (71\% and 58\%, respectively (Cadenas et al. 2008; Iacovacci et al. 2017), the frequency of this haplogroup in Bahrain is just 23\%, being highest in the largely desert Southern Governorate where ethnic Arabs are most common and declining in the more urban areas where the Persian Ajam and indigenous Baharna are most numerous. The diverse haplogroup composition hints at the variety of peoples who have left their mark on Bahrain with B2, E1b1a and E2 originating in Africa and $\mathrm{H}, \mathrm{L}$ and $\mathrm{R} 2$ indicative of migration from South Asia, while the R1b haplotypes may result from the period of Portuguese rule from 1521 to 1602 . We observed haplotypes predicted to belong to both primary branches of R1b, namely R1b1aL754 $(n=10)$ and R1b1b-PH155 $(n=5)$ : while R1b1a is by far the commonest worldwide and likely reflects European contact, the five examples predicted to belong to the very scarce basal haplogroup R1b1b-PH155 all carried a distinctive 25.1 intermediate allele at DYS481, showing that distinctive globally rare variants can locally reach high frequencies and emphasizing the relevance of appropriate regional databases.

In conclusion, we have characterized the paternal lineages of Bahrain, an island nation with a geographical and census size smaller than that of many modern cities. Based on data)), and other datasets from the region: Saudi Arabia $(n=597$ (Khubrani et al. 2018)), Iraq ( $n=1354$ (Purps et al. 2014)), Iran $(n=2333$ (Nasidze et al. 2003; Alshamali et al. 2009; Roewer et al. 2009)); Kuwait ( $n=534$ (Triki-Fendri et al. 2010; Taqi et al. 2015)), UAE $(n=809$ (Nazir et al. 2016)), Yemen $(n=149$ (YHRD data)) and Lebanon ( $n=555$ (YHRD data))

the 27 Y-STRs in the Yfiler Plus multiplex kit, we observe a high and significant degree of differentiation between Bahrain's four governorates (Northern, Southern, Muharraq, and Capital) which likely reflects differences in ethnic composition, in particular past contributions from the Arabian Peninsula, Africa and South Asia. We also observe an unusually high proportion of closely related haplotypes, the majority of which are found within, rather than between, governorates. Again, this reflects ethnic differences, exacerbated by the rapid population growth of the last 70 years. In the forensic context, our characterization of the high degree of population structure in Bahrain will aid in interpreting Y-STR evidence, and the much increased haplotype resolution offered by the Yfiler Plus kit compared to earlier multiplexes will be particularly valuable in improving discrimination power in this country.

Acknowledgements We would like to thank the authorities in Bahrain Forensic Science Lab, Mr. Abdulaziz Mayoof Alrumaihi, Mr. Raed Ali Almaeeli and Mr. Mohammed A. Ghayyath for allowing us to utilize the Bahrain Forensic Science Laboratory. Also, many thanks to Latifa Ahmed and Sabah Nazir for their technical support. Finally, many thanks to Dr. Mohammad A. Alenizi, Mr. Yasser Alaraibi for their valuable feedback and continuous support. This research did not receive any specific grant from funding agencies in the public, commercial, or not-for-profit sectors.

Author contributions Conceptualization: Noora R. Al-Snan, Safia A. Messaoudi, Moiz Bakhiet; Investigation: Noora R. Al-Snan; Formal analysis: Noora R. Al-Snan, Jon H. Wetton, Yahya M. Khubrani; Writing-original draft preparation: Noora R. Al-Snan; Writing—review and editing: Jon H. Wetton, Mark A. Jobling, Yahya M. Khubrani, Safia 
A. Messaoudi, Moiz Bakhiet; Visualization: Jon H. Wetton, Mark A. Jobling; Supervision: Safia A. Messaoudi, Moiz Bakhiet.

\section{Compliance with ethical standards}

Conflict of interest The authors declare that they have no conflict of interest.

Ethics approval All procedures performed in studies involving human participants were in accordance with the ethical standards of the Research and Research Ethics Committee (RREC) (E007-PI-10/17) in the Arabian Gulf University and with the 1964 Helsinki declaration and its later amendments or comparable ethical standards.

Open Access This article is licensed under a Creative Commons Attribution 4.0 International License, which permits use, sharing, adaptation, distribution and reproduction in any medium or format, as long as you give appropriate credit to the original author(s) and the source, provide a link to the Creative Commons licence, and indicate if changes were made. The images or other third party material in this article are included in the article's Creative Commons licence, unless indicated otherwise in a credit line to the material. If material is not included in the article's Creative Commons licence and your intended use is not permitted by statutory regulation or exceeds the permitted use, you will need to obtain permission directly from the copyright holder. To view a copy of this licence, visit http://creativecommons.org/licenses/by/4.0/.

\section{References}

Abdulla MA, Zain al-'Abdeen B (2009) Modern History of Bahrain (1500-2002) University of Bahrain, Bahrain: Historical Studies Centre

Adnan A, Ralf A, Rakha A, Kousouri N, Kayser M (2016) Improving empirical evidence on differentiating closely related men with RM Y-STRs: a comprehensive pedigree study from Pakistan. Forensic Sci Int Genet 25:45-51

Al-Arrayed S, Hamamy H (2012) The changing profile of consanguinity rates in Bahrain, 1990-2009. J Biosoc Sci 44:313-319

al-Khūrī FāI (1980) Tribe and state in Bahrain: The transformation of social and political authority in an Arab state. University of Chicago

Al-Snan NR, Messaoudi S, Babu Bakhiet RSM (2019) Population genetic data of the 21 autosomal STRs included in GlobalFiler kit of a population sample from the Kingdom of Bahrain. PLoS ONE 14:e0220620

Alshamali F, Pereira L, Budowle B, Poloni ES, Currat M (2009) Local population structure in Arabian Peninsula revealed by Y-STR diversity. Hum Hered 68:45-54

Athey TW (2006) Haplogroup prediction from Y-STR values using a Bayesian-allele-frequency approach. J Genet Geneal 2:34-39

Balaresque P, King TE, Parkin EJ, Heyer E, Carvalho-Silva D, Kraaijenbrink T, de Knijff P, Tyler-Smith C, Jobling MA (2014) Gene conversion violates the stepwise mutation model for microsatellites in Y-chromosomal palindromic repeats. Hum Mut 35:609-617

Ballantyne KN, Goedbloed M, Fang R, Schaap O, Lao O, Wollstein A, Choi Y, van Duijn K, Vermeulen M, Brauer S (2010) Mutability of Y-chromosomal microsatellites: rates, characteristics, molecular bases, and forensic implications. Am J Hum Genet 87:341-353

Ballantyne KN, Kayser M (2012) Additional Y-STRs in forensics: why, which, and when. Forensic Sci Rev 24:63-78
Ballantyne KN, Ralf A, Aboukhalid R, Achakzai NM, Anjos MJ, Ayub Q, Balažic J, Ballantyne J, Ballard DJ, Berger B (2014) Toward male individualization with rapidly mutating Y-chromosomal short tandem repeats. Hum Mut 35:1021-1032

Bandelt H-J, Forster P, Röhl A (1999) Median-joining networks for inferring intraspecific phylogenies. Mol Biol Evol 16:37-48

Budowle B, Aranda XG, Lagace RE, Hennessy LK, Planz JV, Rodriguez M, Eisenberg AJ (2008) Null allele sequence structure at the DYS448 locus and implications for profile interpretation. Int J Legal Med 122:421-427

Cadenas AM, Zhivotovsky LA, Cavalli-Sforza LL, Underhill PA, Herrera RJ (2008) Y-chromosome diversity characterizes the Gulf of Oman. Eur J Hum Genet 16:374-386

Ćetković GM, Nevski A (2016) Y-DNA haplogroup predictor-NevGen de Knijff P, Kayser M, Caglià A, Corach D, Fretwell N, Gehrig C, Graziosi G, Heidorn F, Herrmann S, Herzog B, Hidding M, Honda K, Jobling M, Krawczak M, Leim K, Meuser S, Meyer E, Oesterreich W, Pandya A, Parson W, Penacino G, Perez-Lezaun A, Piccinini A, Prinz M, Roewer L (1997) Chromosome Y microsatellites: population genetic and evolutionary aspects. Int J Legal Med 110:134-149

Excoffier L, Lischer HE (2010) Arlequin suite ver 3.5: a new series of programs to perform population genetics analyses under Linux and Windows. Mol Ecol Res 10:564-567

Ferri G, Robino C, Alu M, Luiselli D, Tofanelli S, Caciagli L, Onofri V, Pelotti S, Di Gaetano C, Crobu F (2008) Molecular characterisation and population genetics of the DYS458. 2 allelic variant. Forensic Sci Int Genet Suppl Ser 1:203-205

Fuccaro N (2009) Histories of city and state in the Persian Gulf: Manama since 1800. Cambridge University Press, Cambridge

Gopinath S, Zhong C, Nguyen V, Ge J, Lagacé RE, Short ML, Mulero JJ (2016) Developmental validation of the Yfiler ${ }^{\circledR}$ Plus PCR Amplification Kit: An enhanced Y-STR multiplex for casework and database applications. Forensic Sci Int Genet 24:164-175

Gouy A, Zieger M (2017) STRAF-A convenient online tool for STR data evaluation in forensic genetics. Forensic Sci Int Genet 30:148-151

Guo F (2017) Population genetic data for 12 X-STR loci in the Northern Han Chinese and StatsX package as tools for population statistics on X-STR. Forensic Sci Int Genet 26:e1-e8

Gusmão L, Butler JM, Linacre A, Parson W, Roewer L, Schneider PM, Carracedo A (2017) Revised guidelines for the publication of genetic population data. Forensic Sci Int Genet 30:160-163

Hitti PK, Murgotten FC (1916) The Origins of the Islamic State, Being a Translation from the Arabic, Accompanied with Annotations, Geographic and Historic Notes of the Kitâb Fitûh Al-buldân of Al-Imâm Abu-1 Abbâs Ahmad Ibn-Jâbir Al-Balâdhuri. Columbia university

Holes C (2001) Dialect, Culture, and Society in Eastern Arabia: Glossary. Brill

Iacovacci G, D’Atanasio E, Marini O, Coppa A, Sellitto D, Trombetta B, Berti A, Cruciani F (2017) Forensic data and microvariant sequence characterization of 27 Y-STR loci analyzed in four Eastern African countries. Forensic Sci Int Genet 27:123-131

Karafet TM, Mendez FL, Meilerman MB, Underhill PA, Zegura SL, Hammer MF (2008) New binary polymorphisms reshape and increase resolution of the human Y chromosomal haplogroup tree. Genome Res 18:830-838

Khubrani YM, Wetton JH, Jobling MA (2018) Extensive geographical and social structure in the paternal lineages of Saudi Arabia revealed by analysis of 27 Y-STRs. Forensic Sci Int Genet 33:98-105

Lawson FH (1989) Bahrain: The modernization of autocracy. Westview Press 
McCoy EA (2008) Iranians in Bahrain and the United Arab Emirates: migration, minorities, and identities in the Persian Gulf Arab States. University of Arizona, Tucson

Nasidze I, Schadlich H, Stoneking M (2003) Haplotypes from the Caucasus, Turkey and Iran for nine Y-STR loci. Forensic Sci Int 137:85-93

Nazir M, Alhaddad H, Alenizi M, Alenizi H, Taqi Z, Sanqoor S, Alrazouqi A, Hassan A, Alfalasi R, Gaur S, Al Jaber J, Ziab J, AlHarbi E, Moura-Neto RS, Budowle B (2016) A genetic overview of 23Y-STR markers in UAE population. Forensic Sci Int Genet 23:150-152

Nei M, Tajima F (1981) DNA polymorphism detectable by restriction endonucleases. Genetics 97:145-163

Olofsson JK, Mogensen HS, Buchard A, Børsting C, Morling N (2015) Forensic and population genetic analyses of Danes, Greenlanders and Somalis typed with the Yfiler ${ }^{\circledR}$ Plus PCR amplification kit. Forensic Sci Int Genet 16:232-236

Pickrahn I, Müller E, Zahrer W, Dunkelmann B, Cemper-Kiesslich J, Kreindl G, Neuhuber F (2016) Yfiler® Plus amplification kit validation and calculation of forensic parameters for two Austrian populations. Forensic Sci Int Genet 21:90-94

Purps J, Siegert S, Willuweit S, Nagy M, Alves C, Salazar R, Angustia SM, Santos LH, Anslinger K, Bayer B, Ayub Q, Wei W, Xue Y, Tyler-Smith C, Bafalluy MB, Martinez-Jarreta B, Egyed B, Balitzki B, Tschumi S, Ballard D, Court DS, Barrantes X, Bassler G, Wiest T, Berger B, Niederstatter H, Parson W, Davis C, Budowle B, Burri H, Borer U, Koller C, Carvalho EF, Domingues PM, Chamoun WT, Coble MD, Hill CR, Corach D, Caputo M, D'Amato ME, Davison S, Decorte R, Larmuseau MH, Ottoni C, Rickards O, Lu D, Jiang C, Dobosz T, Jonkisz A, Frank WE, Furac I, Gehrig C, Castella V, Grskovic B, Haas C, Wobst J, Hadzic G, Drobnic K, Honda K, Hou Y, Zhou D, Li Y, Hu S, Chen S, Immel UD, Lessig R, Jakovski Z, Ilievska T, Klann AE, Garcia CC, de Knijff P, Kraaijenbrink T, Kondili A, Miniati P, Vouropoulou M, Kovacevic L, Marjanovic D, Lindner I, Mansour I, Al-Azem M, Andari AE, Marino M, Furfuro S, Locarno L, Martin P, Luque GM, Alonso A, Miranda LS, Moreira H, Mizuno N, Iwashima Y, Neto RS, Nogueira TL, Silva R, Nastainczyk-Wulf M, Edelmann J, Kohl M, Nie S, Wang X, Cheng B, Nunez C, Pancorbo MM, Olofsson JK, Morling N, Onofri V, Tagliabracci A, Pamjav H, Volgyi A, Barany G, Pawlowski R, Maciejewska A, Pelotti S, Pepinski W, Abreu-Glowacka M, Phillips C, Cardenas J, Rey-Gonzalez D, Salas A, Brisighelli F, Capelli C, Toscanini U, Piccinini A, Piglionica M, Baldassarra SL, Ploski R, Konarzewska M, Jastrzebska E, Robino C, Sajantila A, Palo JU, Guevara E, Salvador J, Ungria MC, Rodriguez JJ, Schmidt U, Schlauderer N, Saukko P, Schneider PM, Sirker M, Shin KJ, Oh YN, Skitsa I, Ampati A, Smith TG, Calvit LS, Stenzl V, Capal T, Tillmar A, Nilsson H, Turrina S, De Leo D, Verzeletti A, Cortellini V, Wetton JH, Gwynne GM, Jobling MA, Whittle MR, Sumita DR, Wolanska-Nowak P, Yong RY, Krawczak M, Nothnagel M, Roewer L (2014) A global analysis of Y-chromosomal haplotype diversity for 23 STR loci. Forensic Sci Int Genet 12C:12-23

Rapone C, D'Atanasio E, Agostino A, Mariano M, Papaluca MT, Cruciani F, Berti A (2016) Forensic genetic value of a 27 Y-STR loci multiplex (Yfiler® Plus kit) in an Italian population sample. Forensic Sci Int Genet 21:e1-e5
Roewer L (2009) Y chromosome STR typing in crime casework. Forensic Sci Med Pathol 5:77-84

Roewer L (2017) The Y-Chromosome Haplotype Reference Database (YHRD) — publicly available reference and research datasets for the forensic interpretation of Y-chromosome STR profiles. In: Budowle B (ed) Amorim A. Handbook of Forensic Genetics, Biodiversity and Heredity in Civil and Criminal Investigation. World Scientific, pp 231-248

Roewer L, Willuweit S, Stoneking M, Nasidze I (2009) A Y-STR database of Iranian and Azerbaijanian minority populations. Forensic Sci Int Genet 4:e53-55

Spólnicka M, Dąbrowska J, Szabłowska-Gnap E, Pałeczka A, Jabłońska M, Zbieć-Piekarska R, Pięta A, Boroń M, Konarzewska M, Kostrzewa G, Płoski R, Rogalla U, Woźniak M, Grzybowski T (2017) Intra- and inter-population analysis of haplotype diversity in Yfiler. Forensic Sci Int Genet 28:e22-e25

Taqi Z, Alenizi M, Alenizi H, Ismael S, Dukhyil AA, Nazir M, Sanqoor S, Al Harbi E, Al-Jaber J, Theyab J, Moura-Neto RS, Budowle B (2015) Population genetics of 23 Y-STR markers in Kuwaiti population. Forensic Sci Int Genet 16:203-204

Triki-Fendri S, Alfadhli S, Ayadi I, Kharrat N, Ayadi H, Rebai A (2010) Genetic structure of Kuwaiti population revealed by Y-STR diversity. Ann Hum Biol 37:827-835

Wang C-z, Su M-j, Li Y, Chen L, Jin X, Wen S-q, Tan J, Shi M-s, Li $H$ (2019) Genetic polymorphisms of 27 Yfiler ${ }^{\circledR}$ Plus loci in the Daur and Mongolian ethnic minorities from Hulunbuir of Inner Mongolia Autonomous Region. China, Forensic Sci Int Genet

Wang Y, Zhang YJ, Zhang CC, Li R, Yang Y, Ou XL, Tong DY, Sun HY (2016) Genetic polymorphisms and mutation rates of 27 Y-chromosomal STRs in a Han population from Guangdong Province, Southern China. Forensic Sci Int Genet 21:5-9

Watahiki H, Fujii K, Fukagawa T, Mita Y, Kitayama T, Mizuno N (2019) Polymorphisms and microvariant sequences in the Japanese population for $25 \mathrm{Y}$-STR markers and their relationships to Y-chromosome haplogroups. Forensic Sci Int Genet

Willuweit S, Roewer L (2015) The new Y chromosome haplotype reference database. Forensic Sci Int Genet 15:43-48

Xie M, Song F, Li J, Lang M, Luo H, Wang Z, Wu J, Li C, Tian C, Wang W, Ma H, Song Z, Fan Y, Hou Y (2019) Genetic substructure and forensic characteristics of Chinese Hui populations using 157 Y-SNPs and 27 Y-STRs. Forensic Sci Int Genet 41:11-18

Ye Y, Gao J, Fan G, Liao L, Hou Y (2015) Population genetics for 23 Y-STR loci in Tibetan in China and confirmation of DYS448 null allele. Forensic Sci Int Genet 16:e7-e10

Zgonjanin D, Alghafri R, Antov M, Stojiljković G, Petković S, Vuković R, Drašković D (2017) Genetic characterization of 27 Y-STR loci with the Yfiler® Plus kit in the population of Serbia. Forensic Sci Int Genet 31:e48-e49

Publisher's Note Springer Nature remains neutral with regard to jurisdictional claims in published maps and institutional affiliations. 